\title{
Comparison of the marginal fit of different coping materials and designs produced by computer aided manufacturing systems
}

\author{
Özge KARATAŞLI, Pınar KURSOĞLU, Nuray ÇAPA and Ender KAZAZOĞLU \\ Department of Prosthodontics, Faculty of Dentistry, Yeditepe University, Bağdat Cad. No:238 Göztepe, 34728, Istanbul, Turkey
Corresponding author, Nuray ÇAPA; E-mail: capanuray@yahoo.com
}

\begin{abstract}
In this study, marginal adaptations of different copings fabricated with CAD/CAM or MAD/CAM were analysed. Celay and Zirkonzahn groups were fabricated by MAD/CAM, LAVA and DC-Zircon groups were fabricated by CAD/CAM. Casting metal copings were used as the control group. An implant abutment that was embedded in octagonal acrylic block was used to prepare the copings. Sixteen previously established points were marked and the measurements were performed with the stereomicroscope $($ at $\times 150)$. The marginal fit of the samples were evaluated by calculating the mean measurements of each 16 points. The statistical analysis was performed by Tukey multiple comparisons test at $95 \%$ confidence interval. The groups can be summarized as follows in terms of marginal gap, from the lowest to highest: LAVA $(24.6 \pm 14.0 \mu \mathrm{m})<$ Celay $(64.9 \pm 25.2 \mu \mathrm{m})<$ DC-Zircon $(110.1 \pm 36.5 \mu \mathrm{m})<$ Zirkonzahn $(112.11 \pm 22.6 \mu \mathrm{m})<$ Metal $(120.1 \pm 33.1 \mu \mathrm{m})$. Usage of CAD/CAM or MAD/CAM systems may not be the most important factor for marginal adaptation.
\end{abstract}

Keywords: CAD/CAM (computer-aided design/computer-assisted manufacturing), MAD/CAM (manual aided design/computerassisted manufacturing), Marginal gap

\section{INTRODUCTION}

Increasing expectations of high esthetics, biocompatibility and strength have led to numerous improvements in ceramic restoration. Recently developed yttria-stabilized tetragonal zirconia polycrystal (Y-TZP) and transformation toughening have resulted in a breakthrough in the field of esthetic full-veneer restorations. As a result, high-strength zirconia is now being used in the production of fixed partial prostheses, even in load-bearing areas ${ }^{1-4)}$. The In-Ceram ${ }^{\circledR}$ ZIRCONIA (Vita Zahnfabrik, Säckingen, Germany) system combines the use of glass-infiltrated alumina with $35 \%$ partiallystabilized zirconia for core materials. Similarly to the VITA In-Ceram ${ }^{\circledR}$ ALUMINA system, this ceramic uses a slipcasting technique or milling-out of prefabricated partially-sintered blanks to create the framework ${ }^{1,4,5)}$.

Specifically, copings of zirconia or aluminareinforced with zirconia based porcelain restorations can be produced by manual-aided design and computerassisted manufacturing (MAD/CAM) or computer-aided design and computer-assisted manufacturing (CAD/ CAM). CAD/CAM rapidly provides reproducible results fulfilling certain standards and reduces the errors arising from the technician. However, it is associated with higher costs. On the other hand, MAD/CAM is an easy to use system with low costs and it is not associated with computerized difficulties.

Zirconia or alumina-based materials have many advantages such as biocompatibility, low bacterial adhesion, traditional cementation and perfect mechanical properties. However, high durability of dental restoration is not only the result of mechanical properties. Marginal gaps can cause carious teeth, cement resolution, defected margins, subgingival microflora changes, periodontal destruction and periapical lesions resulting in pulpal effect. For these reasons, marginal fit plays a significant role in the longevity of restorations ${ }^{6-9}$.

This aim of study compared the marginal fit of four different coping materials created by MAD/CAM or $\mathrm{CAD} /$ CAM. Traditional casting metal copings were used in the control group. It was hypothesized that the copings fabricated by CAD/CAM system utilizing computer technology would be associated with less marginal gap.

\section{MATERIALS AND METHODS}

An implant abutment (TiDesign 4.5/5.0, diameter: 6.5, 3 mm, 24238, Astra Tech AB, Mölndal, Sweden) with chamfer finish line and $6^{\circ}$ taper angle was used to produce the copings. A stainless steel octagonal mold (Fig. 1) was created and filled with cold acrylic (Meliodent, Heraeus Kulzer, Senden, Germany). Before acrylic polymerization, the abutment was seated in the acrylic, exposing its cervical area. The octagonal mold was separated after acrylic polymerization and finally, a measurement block consisting of an abutment-fixed octagonal acrylic block was manufactured (Fig. 2). The thickness of the coping was $0.5 \mathrm{~mm}$ all around, simulating the conical structure of the abutment (Fig. 2). Sixteen reference points, including all corners and midpoints of the edges were marked (Fig. 3). Projections of these points were marked on every coping located on the abutment. Marked points on copings were used as measurement points. The octagonal structure of the measurement block enabled measurements from 16 points and allowed the samples to be examined parallel to the focal plane of the microscope. Then, the marginal gap was measured for marginal fit as described by Holmes et al. ${ }^{10)}$.

Four different coping materials were used in this study (Table 1): Celay and Zirkonzahn (Zr-Zahn) were 
fabricated by MAD/CAM, and LAVA and DC-Zircon (DCS) were fabricated by CAD/CAM. Casting metal copings were used in the control group. Groups consisted of 10 samples $(n=10)$.

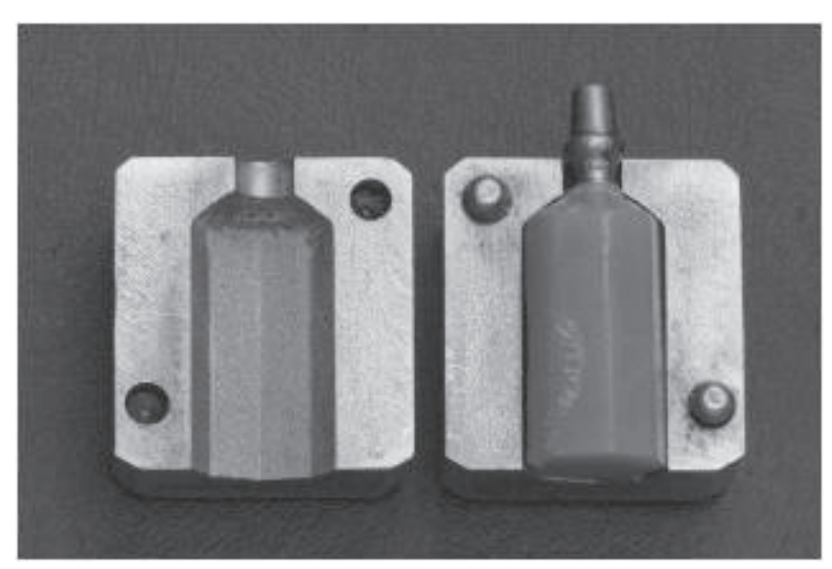

Fig. 1 A stainless steel octagonal mold.
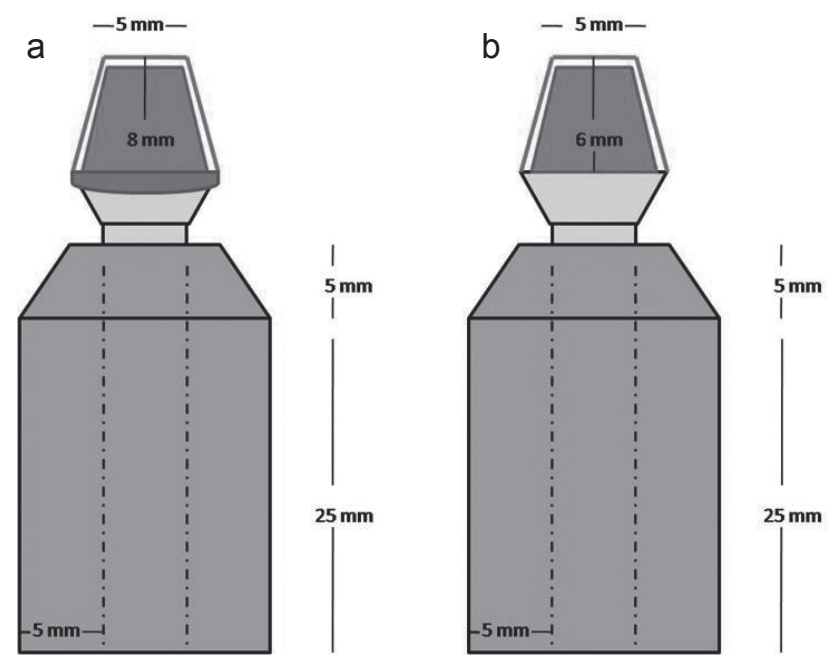

Fig. 2 The measurement block consisting of an abutment-fixed octagonal acrylic block and a; coping view front, b; coping view back.

\section{Coping preparation}

Celay: Copings were prepared on abutment with pattern resin. They were attached to the coping side of the copy-milling unit (Celay, Mikrona Technologie AG, Spreitenbach, Switzerland), while the Alumina blank reinforced with Zirconia (In-Ceram ${ }^{\circledR}$ ZIRCONIA, Vita Zahnfabrik, Bad Säckingen, Germany) was attached at the milling side. Copings were infiltrated with glass at $1,100^{\circ} \mathrm{C}$ for 1.5 hours in an oven (VITA VACUMAT ${ }^{\circledR} 40$ T, Vita Zahnfabrik, Bad Säckingen, Germany). After removal from the oven, bulges and discrepancies were removed with a bur.

Zr-Zahn: Copings were prepared on the abutment with pattern resin. They were fixed and processed by a manual Zr-Zahn milling unit (Zirkograph 025 ECO, Zirkonzahn $\mathrm{GmbH}$, Gais, Italy). The milling procedure was performed in Zr-Zahn blanks (Zirkonzahn $\mathrm{GmbH}$, Gais, Italy). Sintering was performed in a sintering furnace (Zirkonofen 600/V2, Zirkonzahn GmbH, Gais, Italy) at $500^{\circ} \mathrm{C}$ for eight hours. After sintering, bulges and discrepancies were removed with a bur. Coping with pattern resin was performed by the same technician for all MAD/CAM forms.

LAVA: Abutment used for coping preparation was scanned by Lava ${ }^{\mathrm{TM}}$ ScanST (3M ESPE, St. Paul, MN, USA) and copings were designed using Lava Design

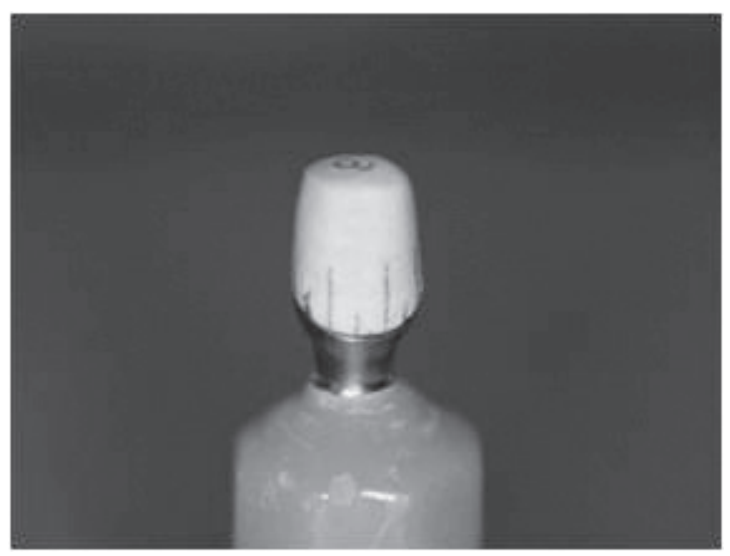

Fig. 3 Measurement points of the copings.

Table 1 Coping materials used in the study

\begin{tabular}{lll}
\hline Materials & Blanks & Manufacturer \\
\hline Celay & $\mathrm{Al}_{2} \mathrm{O}_{3} / \mathrm{ZrO}_{2}$ (Alumina blanks reinforced with zirconia) & Vita, Bad Säckingen, Germany \\
Zr-Zahn & Yttrium-stabilized zirconia & Vita Zahnfabrik, Gais, Italy \\
LAVA & Yttrium-stabilized zirconia & 3M ESPE, Seafeld, Germany \\
& HIP-zirconia & \\
DCS & $62 \% \mathrm{Ni}, 25 \% \mathrm{Cr}, 9.5 \% \mathrm{Mo}, 3.5 \% \mathrm{Si}$ & $\begin{array}{l}\text { SCS Dental AG, Allschwil, } \\
\text { Metal alloy }\end{array}$ \\
\end{tabular}


software. Following the designs, copings were created from LAVA blanks (Lava ${ }^{\mathrm{TM}}$ Frame Zirconia, 3M ESPE, St. Paul, MN, USA) in a milling unit (Lava ${ }^{\mathrm{TM}}$ Form milling system, 3M ESPE, St. Paul, MN, USA). Then, they were stored under room temperature for 3.5 hours as a preliminary drying procedure. Then, the temperature was gradually increased to $1,500^{\circ} \mathrm{C}$ in 2.5 hours and sintering was completed in 2 hours. The sintering process, which lasted for approximately eight hours, was performed in the LavaTerm sintering unit (Lava $^{\mathrm{TM}}$ Furnace 200, 3M ESPE, St. Paul, MN, USA). Following sintering, bulges and discrepancies were removed with a bur.

DCS: All surfaces of abutment used for coping preparation were covered with Dayr spray before scanning, since the scanning unit (Press Scan, DCS Dental AG, Allschwil, Switzerland) could only detect white. Design was performed with DentForm software (DCS Dental AG, Allschwil, Switzerland). DC-Zircon block was not subjected to sintering because it was already sintered. Fully-sintered DCS blanks (DC-Zircon, DCS Dental AG, Allschwil, Switzerland) were attached to a milling machine (Precimill, DCS Dental AG, Allschwil, Switzerland). Preparation was completed in approximately 3 hours. After milling, bulges and discrepancies were removed with a bur.

Metal alloy: A metal coping group was used as the control group. Wax patterns were prepared for metal copings. Care was taken to follow manufacturer's instructions. Using non-noble metal alloy (Mealloy, Dentsply MEA\&CIS Division, Roma, Italy), metal copings were produced in the casting machine (Seit Elettronica SrI, DS1 Topcast, Valdobbiadene, Italy) in $1,450^{\circ} \mathrm{C}$. After casting, refractory residues were cleaned by sandblasting. Then, bulges and discrepancies were removed with a bur.

All copings were then cleaned with steam and dried with compressed air. In addition, all copings were checked with a caliper (Jensen JP-1 JDC 28-337-10, Metzingen, Germany) and were reprocessed to fix the thicknesses at $0.5 \mathrm{~mm}$.

The first measurement was taken from the marked reference point of every coping. Then, the measurement block was rotated carefully and 16 measurements were taken, respectively. Samples were examined at $\times 150$ magnification with a Leica MZ 16 FA stereomicroscope
(Leica Microsystems Ltd, Heerbrugg, Switzerland) A Leica DFC 320 camera (Leica Microsystems Imaging Solutions Ltd, Cambridge, United Kingdom) and Leica Image manager IM 1000 V 4.0 R117 (Leica Microsystems Ltd, Heerbrugg, Switzerland) software were used. The arithmetic mean of 16 points was calculated. Three copings from MAD/CAM, CAD/CAM and the control group were selected randomly to evaluate surveyor reliability. All copings were measured by the same operator and values were compared.

NCSS 2007 was used for statistical analysis. In addition to descriptive statistics (mean, standard deviation), one-way analysis of variance (ANOVA) was used to detect the differences between groups and Tukey multiple comparison test was used for pair-wise comparisons. Statistical tests were performed with alpha levels equal to 0.05 (Table 2).

\section{RESULTS}

Surveyor reliability was high, with an $\mathrm{R}$ value of 0.818 . The marginal gap mean value for Celay material was significantly less than Zr-Zahn, DCS and metal materials ( $p=0.003, p=0.005, p=0.001)$, but was significantly higher than marginal gap mean values for LAVA $(p=0.016)$ (Table 2, 3).

The mean marginal gap value of $\mathrm{Zr}$-Zahn material was significantly higher than that of marginal gap values for LAVA and Celay materials ( $p=0.001, p=0.003)$. In addition, there was no significant difference between mean marginal gap values for Zr-Zahn and DCS or the metal group ( $p>0.05$ and $p>0.05$, respectively).

LAVA material had the least mean marginal gap value among DCS, Zr-Zahn, Celay and metal groups ( $p=0.001, p=0.001, p=0.016$ and $p=0.001$, respectively) (Table 3). DCS material had significantly higher mean marginal gap value than LAVA and Celay materials ( $p=0.001$ and $p=0.005$, respectively). There were no significant differences between the mean marginal gap values of DCS and Zr-Zahn materials ( $p>0.05$ ) (Table 3).

Marginal adaptation is listed from best to worst as follows: LAVA $(24.6 \pm 14.0 \mu \mathrm{m})<$ Celay $(64.9 \pm 25.2 \mu \mathrm{m})<$ DCS $(110.1 \pm 36.5 \mu \mathrm{m})<$ Zr-Zahn $(112.1 \pm 22.6 \mu \mathrm{m})<$ Metal $(120.1 \pm 33.1 \mu \mathrm{m})$ ( Fig. $4 \mathrm{a}-\mathrm{e})$.

Table 2 Marginal gap measurement results

\begin{tabular}{lccc}
\hline Groups & Number of samples $(n)$ & $\begin{array}{c}\text { Marginal gap, } \mu \mathrm{m} \\
\text { Mean (SD) }\end{array}$ & $\begin{array}{c}\text { Marginal gap, } \mu \mathrm{m} \\
(\text { range, min-max) }\end{array}$ \\
\hline Celay & 10 & $64.9(25.2)$ & $39.9-123.6$ \\
Zr-Zahn & 10 & $112.1(22.6)$ & $82.6-152.6$ \\
LAVA & 10 & $24.6(14.0)$ & $9.0-44.6$ \\
DCS & 10 & $110.1(36.5)$ & $47.0-177.3$ \\
Metal & 10 & $120.1(33.1)$ & $80.7-162.1$ \\
\hline
\end{tabular}

SD: Standard Deviation 
Table 3 Statistical comparisons of the groups with regard to mean marginal gap values

\begin{tabular}{lc}
\hline Comparison & $p$ value (Tukey test) \\
\hline Celay versus Zr-Zahn & $0.003^{*}$ \\
Celay versus LAVA & $0.016^{*}$ \\
Celay versus DCS & $0.005^{*}$ \\
Celay versus Metal & $0.001^{*}$ \\
Zr-Zahn versus LAVA & $0.001^{*}$ \\
Zr-Zahn versus DCS & 0.998 \\
Zr-Zahn versus Metal & 0.965 \\
LAVA versus DCS & $0.001^{*}$ \\
LAVA versus Metal & $0.001^{*}$ \\
DCS versus Metal & 0.926 \\
\hline
\end{tabular}

* Indicates statistical significance

\section{DISCUSSION}

Marginal adaptation is essential in increasing the long-term success of a restoration ${ }^{11}$. Optimal marginal adaptation is an important factor in the biologic and mechanical stabilization of the fixed prosthesis. Increased marginal discrepancy causes maladjusted restorations and results in a high risk of periodontal diseases and tooth decay ${ }^{7,8,12}$. For full ceramic crowns, a marginal gap between 1 and $165 \mu \mathrm{m}$ is considered acceptable ${ }^{13,14)}$. However, some authors suggest that $100-150 \mu \mathrm{m}$ is acceptable for various restorations ${ }^{15,16)}$. McLean and von Fraunhofer ${ }^{17)}$ recommended $120 \mu \mathrm{m}$ as the maximum acceptable marginal gap value based on the results of a five-year study consisting of 1,000 restorations. In this study, mean marginal gap values of all study groups were below $120 \mu \mathrm{m}$, except for the control group. Control group also had an acceptable borderline value $(120.1 \pm 33.1 \mu \mathrm{m})$.

The mean marginal gap for full ceramic crowns created by CAD/CAM is reported to be $23-74 \mu \mathrm{m}^{6,18,19)}$. In the present study, LAVA zirconia copings created by $\mathrm{CAD} / \mathrm{CAM}$ had similar mean marginal gap value $(24.6 \pm 14.0 \mu \mathrm{m})$; however, DCS had higher results
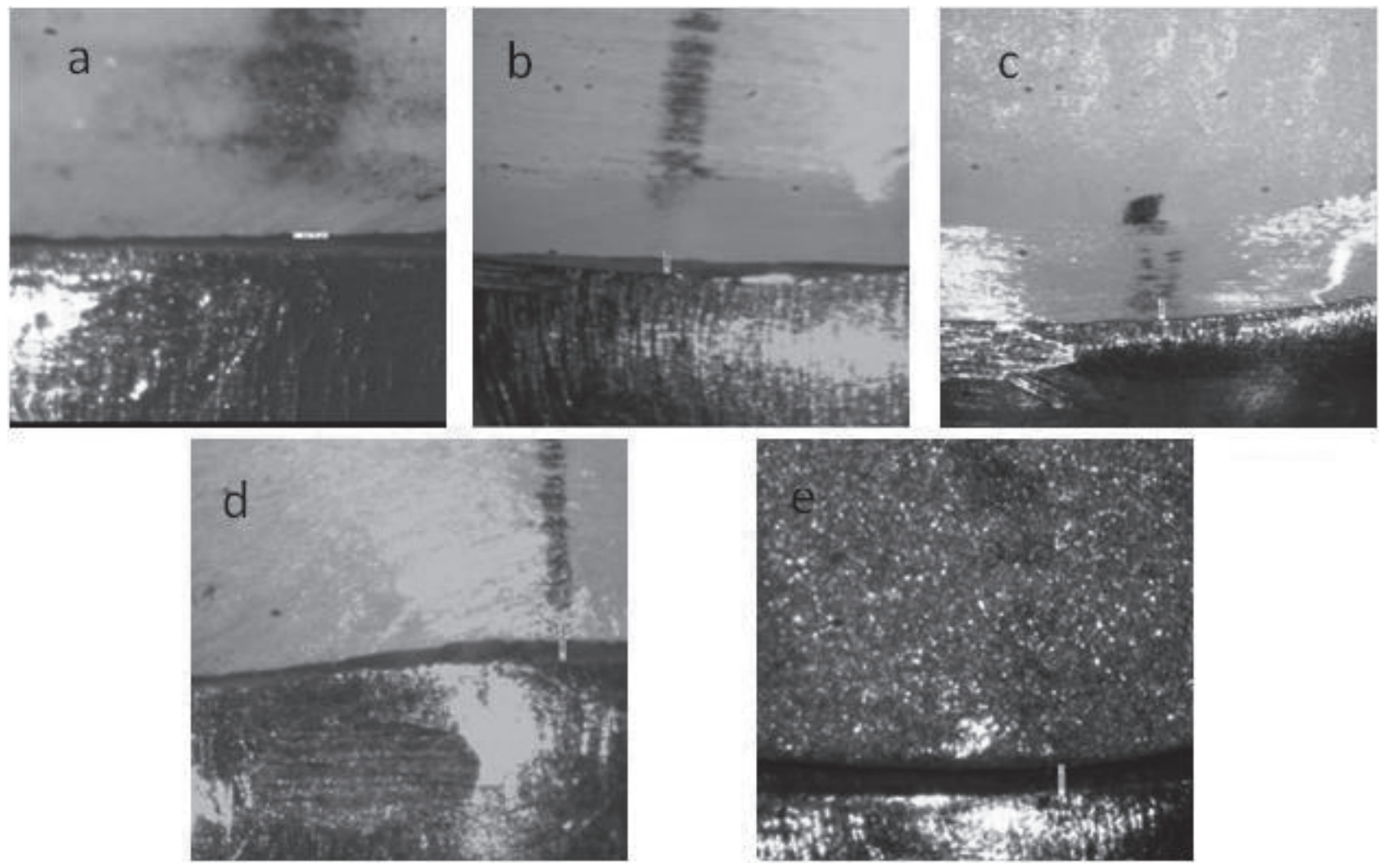

Fig. 4 Marginal fit photograph $(\times 150)$

a: Celay coping

b: Zr-Zahn coping

c: LAVA coping

d: DCS coping

e: Metal coping 
$(110.1 \pm 36.5 \mu \mathrm{m})$. The difference in mean marginal gap values between the two groups of copings created by $\mathrm{CAD} / \mathrm{CAM}$ could be the result of different sintering procedures of zircon blanks. It can also be speculated that the hard structure of zircon blanks, the result of full sintering, may result in inconvenient milling procedures. Therefore, this may decrease the precision of marginal adaptation and explain the results of the present study. Other studies of LAVA ${ }^{20,21)}$ found higher marginal gap values compared to this study, whereas studies of DCS found smaller values ${ }^{6,18)}$. These differences between the present and previous studies may be the result of different measurement techniques and reference locations used, subjective nature of the measurements, and the use of different blank materials.

The mean marginal gap value $(64.89 \mu \mathrm{m})$ of the Celay group created by MAD/CAM was greater than the value determined by Groten et al. ${ }^{22)}(23.0 \mu \mathrm{m})$ and less than the value observed by Yeo et al. ${ }^{23)}(83 \mu \mathrm{m})$. The present study shows that Celay has a significantly smaller marginal gap than the CAD/CAM product DCS, even though it was created by MAD/CAM. Alumina blanks reinforced with zirconia, as opposed to fullsintered zirconia blanks and glass infiltration without sintering, may be responsible for the difference between Celay and DCS systems. Currently, no published studies on the marginal adaptation of the Zr-Zahn system exist in the literature.

There are some differences between single-crown and multiple-unit bridges with regard to marginal adaptation, but they are not statistically significant $t^{6,20,21)}$. Therefore, this study measured multiple points in a single crown. Taper angle of abutment was selected as $6^{\circ}$. In in vitro studies ${ }^{23,24)}$ of marginal adaptation, preparation angles varied between $6^{\circ}$ and $15^{\circ}$. In this study, all groups had same taper angle; it was therefore not considered as a variable effecting marginal adaptation between groups.

Recommended finish line types for optimal marginal adaptation are shoulder, shoulder-bevel and chamfer ${ }^{18)}$. Several studies showed no significant differences between shoulder, shoulder-bevel and chamfer-type finish lines. In this study, chamfer-type was preferred ${ }^{25)}$.

Marginal adaptation has a close relationship with clinical success for fixed restorations, and there are many methods to measure marginal adaptation. The preferred methods are microscopy and cross section $^{7,8,22-24)}$. In this study, a microscopic measurement method was chosen. Results were evaluated with a computer using a digital camera attached to a microscope.

This study compared marginal adaptation of different coping materials fabricated using CAD/CAM or MAD/CAM system, and did not find any superiority of either system over the other. Although CAD/CAM system was used for both LAVA and DCS groups, a significant difference was found in terms of their marginal adaptation. Similarly, Celay and Zr-Zahn groups differed in terms of marginal adaptation, although MAD/CAM system was used for both of them. On the other hand, copings produced by CAD/CAM (DCS), MAD/CAM
(Zr-Zahn) or metal casting techniques had similar marginal gaps, suggesting that the production technique is not the sole factor leading to better results. On the other hand, best results were obtained with LAVA group using $\mathrm{CAD} / \mathrm{CAM}$ system. Based on these findings, only one of the groups using CAD/CAM system provided better results, but the other $\mathrm{CAD} / \mathrm{CAM}$ system did not prove superior to MAD/CAM system, thus not supporting the hypothesis of the present study.

\section{CONCLUSION}

Findings of this study showed that optimal marginal fit does not solely depend on the system used for fabrication. Type of the coping material (zirconium or aluminareinforced with zirconia), partial or full sintering that would modify the hardness of the blanks, and accuracy of milling procedure all seem to have an effect on marginal gap and should be tested in further clinical studies. In the selection of the most suitable restoration for the patient, clinicians must take notice of the properties of the production material rather than the production system. While the utilization of hard coping material increases the fracture resistance of restorations, we believe that it causes difficulty in the processability of the material in both systems. This difficulty in the milling process may increase marginal gap, hence result in poorly adapted restorations clinically.

\section{REFERENCES}

1) Raigrodski AJ. Contemporary materials and technologies for all-ceramic fixed partial dentures: A review of the literature. J Prosthet Dent 2004; 92: 557-562.

2) Yilmaz H, Aydin C, Gul BE. Flexural strength and fracture toughness of dental core ceramics. J Prosthet Dent 2007; 98: 120-128.

3) Guazzato M, Albakry M, Ringer SP, Swain MV. Srength, fracture toughness and microstructure of a selection of all-ceramic materials. Part II. Zirconia-based dental ceramics. Dent Mater 2004; 20: 449-456.

4) Cehreli MC, Kokat AM, Akca K. CAD/CAM zirconia vs. slip-cast glass-infiltrated alumina/zirconia all-ceramic crowns: 2-year results of a randomized controlled clinical trial. J Appl Oral Sci 2009; 17: 49-55.

5) Guazzato M, Albakry M, Quach L, Swain MV. Influence of surface and heat treatments on the flexural strength of a glass-infiltrated alumina/zirconia-reinforced dental ceramic. Dent Mater 2005; 21: 454-463.

6) Tinschert J, Natt G, Mautsch W, Spiekermann H. Marginal fit of alumina- and zirconia-based fixed partial dentures produced by a CAD/CAM system. Oper Dent 2001; 26: 367-374.

7) Albert FE, El-Mowafy OM. Marginal adaptation and mikroleakage of procera all-ceram crowns with four cements. Int J Prosthodont 2004; 17: 529-535.

8) Sorensen JA, Strutz JM, Avera SP, Materdomini D. Marginal fidelity and microleakage of porcelain veneers made by two techniques. J Prosthet Dent 1992; 67: 16-22.

9) Beuer F, Aggstaller H, Edelhoff D, Gernet W, Sorensen J. Marginal and internal fits of fixed dental prostheses zirconia retainers. Dent Mater 2009; 25: 94-102.

10) Holmes JR, Bayne SC, Holland GA, Sulik WD. Considerations in measurement of marginal fit. J Prosthet Dent 1989; 62: 
405-408.

11) Komine F, Gerds T, Witkowski S, Strub JR. Influence of framework configuration on the marginal adaptation of zirconium dioxide ceramic anterior four-unit frameworks. Acta Odontol Scand 2005; 65: 361-366.

12) Lang NP, Kiel RA, Anderhalden K. Clinical and microbiological effects of subgingival restorations with overhanging or clinically perfect margins. J Clin Periodontol 1983; 10: 563-578.

13) Schaerer P, Sato T, Wohlwend A. A comparison of the marginal fit of three cast ceramic crown systems. J Prosthet Dent 1988; 59: 534-542.

14) Sulaiman F, Chai J, Jameson LM, Wozniak WT. A comparison of the marginal fit of In-ceram, IPS Empress and Procera crowns. Int J Prosthodont 1997; 10: 478-484.

15) Boening KW, Walter MH, Reppel PD. Non-cast titanium restorations in fixed prosthodontics. J Oral Rehabil 1992; 19: 281-287.

16) Fransson B, Oilo G, Gjeitanger R. The fit of metal-ceramic crowns: a clinical study. Dent Mater 1985; 1: 197-199.

17) McLean JW, von Fraunhofer JA. The estimation of cement film thickness by an in vivo technique. Br Dent J 1971; 131: 107-111.

18) Bindl A, Mörmann WH. Marginal and internal fit of all-ceramic $\mathrm{CAD} / \mathrm{CAM}$ crown-copings on chamfer preparations.
J Oral Rehabil 2005; 32: 441-447.

19) Coli P, Karlsson S. Fit of a new pressure-sintered zirconium dioxide coping. Int J Prosthodont 2004; 17: 59-64.

20) Vigolo P, Fonzi F. An in vitro evaluation of fit of zirconiumoxide-based ceramic four-unit fixed partial dentures, generated with three different $\mathrm{CAD} / \mathrm{CAM}$ systems, before and after porcelain firing cycles and after glaze cycles. J Prosthet Dent 2008; 17: 621-626.

21) Reich S, Wichmann M, Nkenke E, Proeschel P. Clinical fit of all-ceramic three-unit fixed partial dentures, generated with three different CAD/CAM systems. Eur J Oral Sci 2005; 113: 174-179.

22) Groten M, Grithofer S, Pröbster L. Marginal fit consistency of copy-milled all-ceramic crowns during fabrication by light and scanning electron microscopic analysis in vitro. J Oral Rehabil 1997; 24: 871-881.

23) Yeo I, Yang J, Lee J. In vitro marginal fit of three all-ceramic crown systems. J Prosthet Dent 2003; 90: 459-464.

24) May KB, Russel MM, Razzoog ME, Lang BR. Precision of fit: The Procera All-ceram crown. J Prosthet Dent 1998; 80: 394-404.

25) Pera P, Gilodi S, Bassi F, Carossa S. In-vitro marginal adaptation of alumina porcelain ceramic crowns. J Prosthet Dent 1994; 72: 585-590. 